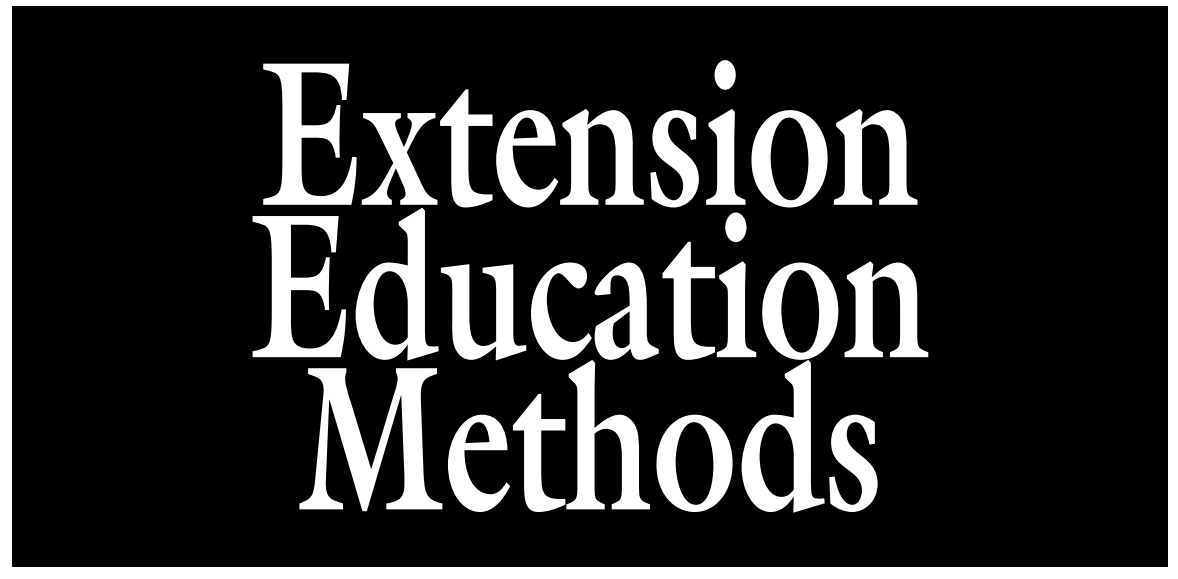

\section{Eat Your Way to Better Health: Evaluating a Garden-based Nutrition Program for Youth}

\author{
Matthew J. Kararo ${ }^{1,3}$, Kathryn S. Orvis ${ }^{2,4,5}$, and Neil A. Knobloch ${ }^{1,4}$
}

AdDitional INDEX wORDs. extension, fruit and vegetable consumption, horticultural education

Summary. Eat Your Way to Better Health (EYWTBH) is a garden-based nutrition education program that was conducted and evaluated for 3 years in Indiana thirdgrade classrooms. Program participants started and maintained their own school gardens as a part of an authentic experiential learning curriculum designed to reconnect youth with where their food comes from and educate about healthy eating habits. Implementation lasted between 8 and 12 weeks and outcomes were evaluated using pre- and postprogram questionnaires. Results showed that upon completion of the EYWTBH program, youth reported a higher healthy food choice self-efficacy, as well as a higher variety of fruit and vegetable consumption.

Relationships among the variables were identified and discussed in the context of improving future school garden nutrition programs.

$\mathrm{E}$ at Your Way to Better Health is a multisensory educational program established to reconnect youth with their food by having them grow and taste produce in an effort to provide education about healthy eating and increase fruit and vegetable consumption. The program was implemented as an authentic experiential learning garden-based school nutrition program offered in third-grade classrooms across Indiana through a collaborative effort between a land-grant university, county

${ }^{1}$ Department of Youth Development and Agricultural Education, Purdue University, 615 West State Street, West Lafayette, IN 47907

${ }^{2}$ Departments of Youth Development and Agricultural Education, and Horticulture and Landscape Architecture, 615 West State Street, West Lafayette, IN 47907

${ }^{3}$ Doctoral candidate

${ }^{4}$ Associate Professors

${ }^{5}$ Corresponding author. E-mail: orvis@purdue.edu. doi: 10.21273/HORTTECH03225-16
EYWTBH curriculum was adapted from the Junior Master Gardener ${ }^{\circledR}$ program developed by Texas A\&M University (Junior Master Gardener, 2014). County extension educators partnered with school principals and elementary teachers to deliver $1 \mathrm{~h}$ of instruction per week for 6-10 weeks (length of program depended on localized factors) using curriculum and resources supplied by the university EYWTBH team.

EYWTBH was offered through extension because of the university's local presence in every county in the state. Extension can play a crucial role in addressing critical systemic issues in the surrounding community by being a trustworthy source of information (Awa and Van Crowder, 1978; Smith et al., 2012) and facilitating collaborative and interdisciplinary projects. Food illiteracy is an example of a critical systemic issue that occurs when citizens and youth in local communities do not understand enough about the food system to make healthy food choices. One way this disconnect can manifest itself is through low levels of fruit and vegetable consumption that result in unhealthy eating habits and lead to an increased risk of developing obesity. These issues are present throughout the general population, especially concerning is the prevalence of these unhealthy trends in youth. In the United States, the adult obesity rate is $34.9 \%$ and the youth obesity rate is $16.9 \%$ (Ogden et al., 2014). As such, adults report eating a median of 1.1 servings of fruit and 1.6 servings of vegetables per day (Centers for Disease Control and Prevention, 2013). Those data, along with a presence in the literature of a correlation between parental/guardian with that of peer and youth consumption of fruits and vegetables (Benton, 2004; Blanchette and Brug, 2005; Boutelle et al., 2007; Bower and Sandall, 2002; Brug et al., 2008; Johnson et al., 2007; Libman, 2007; Nanney et al., 2007; RobinsonO'Brien et al., 2009; Scaglioni et al., 2008), show that low levels of fruit and vegetable consumption is a multifaceted issue that requires an integrated solution of local community educators

The EYWTBH program development, implementation, and evaluation were informed by social cognitive theory [SCT (Bandura, $1986,1989)]$. Bandura posited that 
behaviors are influenced by personal and environmental factors. While SCT views knowledge as a personal factor and something that can be transferred by social means, Bandura adds that behavior is mediated by self-efficacy, or one's self-confidence to perform the behavior. Self-efficacy is critical to the point that even if a person has the ability necessary to perform a behavior, if he or she does not think he or she can perform the behavior, it is likely to not occur.

The purpose of this study was to describe differences between pre- and postprogram outcomes, as well as any personal and environmental factors that may be related to the postprogram youth fruit and vegetable consumption outcome. There were two research objectives: 1) determine if youth participants reported higher levels of fruit and vegetable consumption upon completion of the EYWTBH program and 2) determine if selected variables (i.e., youth preprogram fruit and vegetable consumption; postprogram youth healthy food choice self-efficacy, interest/ preferences in fruits and vegetables as a snack, and healthy food social intentions; family postprogram fruit and vegetable consumption; household postprogram fruit and vegetable availability) were related with postprogram youth fruit and vegetable consumption.

\section{Materials and methods}

The EYWTBH program implementation included the following steps: 1) county educators worked with grade school principals and third-grade teachers to determine interested parties, 2) county extension educator trainings were offered, 3) preprogram evaluations were administered to youth in participating classrooms, 4) extension and elementary teachers collaborated to offer EYWTBH lessons weekly for 6-10 weeks, and $5)$ postprogram evaluations were administered to youth in participating classrooms. An example timeline for EYWTBH program implementation included the administration of the preprogram assessment to both youth participants and their parent or guardian; 6-10 weekly lessons were then conducted and followed by the administration of the postprogram assessment to both youth participants and their parent or guardian.

Preprogram training and ORgANIZATION. County extension staff first partnered with local schools agreeing to offer EYWTBH in thirdgrade classrooms on a weekly basis for 6-10 weeks through an e-mail request for participants via extension electronic mailing lists. An informational conference call(s) was used with extension educators to help determine final participants in the program based on availability, readiness of school participants, and willingness to complete the program and associated research. Participation of at least 20 counties was estimated with up to 40 counties per semester ultimately participating over a 3 -year period. About 60 extension educators were involved, although a finite number is hard to determine due to staff changes, and school and community needs and differences.

Following selection, participating extension staff was required to attend a $\mathrm{l} \mathrm{d}(8 \mathrm{~h})$ training session, which included information about the Junior Master Gardener ${ }^{\circledR}$ and EYWTBH programs, as well as potential benefits of the program, such as an increase in nutrition knowledge and an improvement in learning by being in a contextualized multisensory garden environment. EYWTBH lessons were paired with the Junior Master Gardener ${ }^{\circledR}$ Health and Nutrition from the Garden ${ }^{\circledR}$ curriculum, and selected for content and age appropriateness to the third-grade audience. Educators were introduced to research methods and implementation of pre- and postprogram survey instruments. A participatory training methodology (Pant, 2008) was used to teach educators objectives of the lessons. This included active participation of extension staff who completed example youth activities and took part in discussions on the strengths and possible issues with each activity. Participants in the training were provided with EYWTBH program materials consisting of gardening supplies, such as trowels, materials to build raised garden beds, seeds, and funds to purchase fruits and vegetables for tasting.

QUESTIONNAIRE ADMINISTRATION. Before classroom implementation of EYWTBH lessons, extension educators and elementary teachers partnered to administer preprogram questionnaires. At the same time, preprogram questionnaires for the parents/guardians were sent home with youth, along with program information, and instructions for the parent/guardian to complete and return their questionnaire with the student within the following week.

EYWTBH LESSONS. EYWTBH lessons were taught through cooperation between extension educators and elementary teachers. Lessons took place as part of a normal school day once per week for at least $1 \mathrm{~h}$ and were tailored to fit school period length. Each lesson consisted of an overarching topic, construction of nutrition knowledge, disciplined inquiry into nutrition and plant science, and adding value beyond the classroom by connecting food choices and nutrition to the household and family. Ten lessons were matched for the program, as seen in Table 1 , and teachers could select up to eight lessons that best fit the needs of their school and community. Mandatory lessons on gardening and fruits and vegetables were used to anchor the program. In addition to hands-on classroom activities, each lesson contained take-home activities that aimed to engage parents/guardians in the learning process by having meaningful conversations with their child about food and healthy eating. Classroom teachers and extension staff were asked to provide feedback on program success, challenges, and deviations from the expected outcomes. A paper form was used to collect that feedback and those data were used to improve future program implementation.

Classroom garden. To provide an experiential learning opportunity for the youth participants, a classroom garden was requested of each participating school to be started at the beginning of the EYWTBH program, either outdoors or in the classroom under full-spectrum lighting depending on regional gardening conditions. Gardens were installed with provided supplies, and extension staff, school staff, and community volunteers were recruited to help with construction of outdoor garden beds. Easy to germinate and fast-growing seeds were used, including garden pea (Pisum sativum), leaf lettuce (Lactuca sativa), common bean (Phaseolus vulgaris), radish (Raphanus sativus), and 
Table 1. Sample 6-week Eat Your Way to Better Health classroom programming based on Junior Master Gardener ${ }^{\circledR}\left(\right.$ JMG $\left.^{\circledR}\right)$ Health and Nutrition from the Garden ${ }^{\circledR}$ curriculum. $^{\mathrm{z}}$

\begin{tabular}{|c|c|c|c|}
\hline Week no. & $\begin{array}{l}\mathrm{JMG}^{\circledR} \text { lesson or } \\
\text { activity (options) }\end{array}$ & $\begin{array}{l}\text { Objective or goal } \\
\text { or theme }\end{array}$ & Assessment \\
\hline Preprogram & Garden installation and set-up & & $\begin{array}{l}\text { Preprogram questionnaire given; } \\
\text { send home preprogram parent } \\
\text { questionnaire }\end{array}$ \\
\hline 1 & $\begin{array}{l}\text { Cylinder Gardening or Paper Pots } \\
\text { or Paper Towel Gardening }\end{array}$ & Growing techniques & Collect parent survey \\
\hline $3-5^{y}$ & $\begin{array}{l}\text { Choose from: } \\
\text { Bold Molds } \\
\text { Label Reader } \\
\text { Robust Rainbow Recipes } \\
\text { Apple Surprise } \\
\text { Symmetry Snacks } \\
\text { Seed Bank } \\
\text { Junk Food Blues } \\
\text { Taste Test } \\
\text { Beauty Contest } \\
\text { UB the Judge }\end{array}$ & $\begin{array}{l}\text { Healthful snacks, ABCs of healthful } \\
\text { eating, basic knowledge of differences } \\
\text { between fruits and vegetables }\end{array}$ & $\begin{array}{l}\text { Send parent postprogram } \\
\text { questionnaire home week } 5\end{array}$ \\
\hline 6 & Fruit and Veggie Laboratory & $\begin{array}{l}\text { Harvesting, preparing, and sampling } \\
\text { fruits and vegetables; healthful snacks }\end{array}$ & \\
\hline Postprogram & & & $\begin{array}{l}\text { Postprogram questionnaire given; } \\
\text { collect parent questionnaire }\end{array}$ \\
\hline
\end{tabular}

spinach (Spinacia oleracea), so that youth could experience the breadth of the gardening experience, such as planting, watering, weeding, and harvesting, during the length of the program.

PostProgram Questionnaire administration. Postprogram questionnaires for parents/guardians were sent home with youth 1 week before the completion of the program, with instructions to complete and return the questionnaire within $\mathrm{l}$ week. Upon returning the postprogram questionnaire, parents/guardians were provided with a pack of EYWTBH-branded recipe cards containing healthy meal and snack ideas that incorporated vegetables participants potentially grew in the classroom garden during the program. After the classroom and gardening lessons were completed, postprogram questionnaires were administered to youth participants within 1 week by either the extension or elementary teachers. Upon completing postprogram questionnaires, students received EYWTBH certificates of program completion.

INSTRUMENT DESIGN. EYWTBH program evaluation questionnaires measured food behaviors [YFB (33 possibly consumed fruit and vegetable items; participants were presented with a checklist and asked to put an X next to all fruits and vegetables they ate in the past week)], food interest [YFI (27 fruit and vegetable items; participants were presented with a checklist and asked to put an $\mathrm{X}$ next to all fruits and vegetables they liked eating as a snack)], and healthy eating self-efficacy [YSE (11 items on a 4-point Likert-type scale, e.g., "for a snack, I think I can choose my favorite fruit instead of my favorite candy bar" with possible answers being "disagree a lot," "disagree a little," "agree a little," and "agree a lot")] as selfreported by youth participants. Additionally, familial food behaviors [FFB (33 possibly consumed fruit and vegetable items using same checklist as youth questionnaire)] and household food availability [HFA (checklist of 27 possibly available fruit and vegetable items)] were provided by the youth participants' parent/guardian.

Questionnaires were developed by experts in the field of program evaluation, analyzed for content validity (Light, 2007), and tested for readability and appropriateness among 7-to 10-year-old children.
Cronbach $\alpha$ was used as a measure of internal reliability. All reliability coefficients were in the range of acceptable to good (George and Mallery, 2003). Observed coefficients for variables were preprogram $\mathrm{YFB}=$ 0.83 , postprogram YFB $=0.85$; preprogram YFI $=0.85$, postprogram $\mathrm{YFI}=0.85$; preprogram $\mathrm{YSE}=0.86$, postprogram YSE $=0.88 ;$ preprogram $\mathrm{FFB}=0.73$, postprogram $\mathrm{FFB}=0.77$; and preprogram HFA $=0.84$, postprogram HFA $=0.86$.

Data analysis. The study did not have a true control group and thus was conducted using a one group pre-experimental design. Data were collected from 25 different classrooms across Indiana that offered EYWTBH in one of three semesters from 2009 to 2010. Demographics were collected in only one semester, Fall 2010, due to an omission of demographic items from the instrument in previous semesters. Demographics observed were generally representative of Indiana as a whole, with youth data indicating that $78 \%$ of the 222 youth participants during this semester were White and not Hispanic (Indiana population is $\approx 82 \%$ White), and guardian data indicating that the median 
household income of the 111 respondents during this semester was between $\$ 40,000$ and $\$ 60,000$ (Indiana population median household income is $\$ 45,000)$. Statistical analyses were completed using SPSS (SPSS Statistics for Windows version 23.0; IBM, Armonk, NY) and included descriptive statistics, as well as Pearson correlations $(r)$, and paired sample $t$ tests. Differences in interest, behaviors, self-efficacy, and knowledge were deemed statistically significant if $P<0.05$.

\section{Results}

There were three key findings. The first was that five measured variables were significantly correlated with youth postprogram fruit and vegetable consumption (Table 2 ). Youth preprogram fruit and vegetable consumption (pre-YFB) had a strong positive relationship with youth postprogram fruit and vegetable consumption (post-YFB) $(r=0.54)$, while youth postprogram healthy food choice self-efficacy (post-YSE) had a weak positive relationship $(r=$ 0.27 ), family postprogram fruit and vegetable consumption (post-FFB) had a moderate positive relationship $(r=0.31)$, household postprogram fruit and vegetable availability (postHFA) had a moderate positive relationship $(r=0.30)$, and youth postprogram fruit and vegetable interest (post-YFI) had a strong positive relationship $(r=0.58)$. Means and standard deviations, as well as the scales on which the variables were measured, can be seen in Table 3.

The second finding was that upon completion of the EYWTBH

Table 2. Pearson correlations $(r)$ for variables measured by Eat Your Way to Better Health (EYWTBH) pre- and postprogram questionnaires administered to both EYWTBH program participants and their parent/guardian.

\begin{tabular}{lcccccc}
\hline Variable $^{\mathrm{z}}$ & Pre-YFB & Post-YFB & Post-YSE & Post-FFB & Post-HFA & Post-YFI \\
\hline Pre-YFB & 1 & & & & & \\
Post-YFB & $0.54^{*}$ & 1 & & & & \\
Post-YSE & $0.22^{*}$ & $0.27^{*}$ & 1 & & & \\
Post-FFB & $0.26^{*}$ & $0.31^{*}$ & 0.08 & 1 & & \\
Post-HFA & $0.23^{*}$ & $0.30^{*}$ & 0.08 & $0.64^{*}$ & 1 & 1 \\
Post-YFI & $0.44^{*}$ & $0.58^{*}$ & $0.38^{*}$ & $0.21^{*}$ & $0.27^{*}$ & 1 \\
\hline
\end{tabular}

${ }^{2}$ Pre-YFB $=$ youth preprogram fruit and vegetable consumption; post-YFB $=$ youth postprogram fruit and vegetable consumption; post-YSE = youth postprogram healthy food choice self-efficacy; post-FFB = family postprogram fruit and vegetable consumption; post-HFA = household postprogram fruit and vegetable availability; post-YFI $=$ youth postprogram fruit and vegetable interest.

* Significant at $P<0.05$. program, youth reported a higher mean healthy food choice self-efficacy (Table 4). This supports prior research by Gist and Mitchell (1992), which states that self-efficacy, is malleable and can be improved through intervention through mastery and modeling experiences.

The third finding was that youth reported a higher diversity of fruit and vegetable consumption after completing the EYWTBH program (Table 4). This supports prior research that found fruit and vegetable consumption diversity increased after a targeted intervention (Cason, 1999; Heim et al., 2009; Hilgers et al., 2008).

\section{Discussion}

Upon completion of the program, youth reported a higher healthy food choice self-efficacy. This finding was significant because SCT contextualizes self-efficacy as a critical component influencing behavior. If healthy food choice self-efficacy is increased, then this can improve personal factors that relate to healthy food choice behaviors, such as fruit and vegetable consumption. The result of healthy food choice selfefficacy being related to fruit and vegetable consumption also confirms the findings of previous studies (Brug et al., 2008; Reynolds et al., 1999; Strecher et al., 1986; Vereecken et al., 2005), which found that self-efficacy

Table 3. Descriptions and descriptive statistics of variables measured by Eat Your Way to Better Health (EYWTBH) pre- and postprogram questionnaires, administered to both EYWTBH program participants and their parent/guardian.

\begin{tabular}{lrrrr}
\hline Variable reference no. & Mean & SD & Cases (no.) & Scale \\
\hline Youth preprogram fruit and vegetable consumption (pre-YFB) & 9.35 & 6.00 & 905 & 33 possible fruits and vegetables \\
Youth postprogram fruit and vegetable consumption (post-YFB) & 10.69 & 6.24 & 817 & 33 possible fruits and vegetables \\
Youth postprogram healthy food choice self-efficacy (post-YSE) & 3.09 & 0.71 & 762 & 4 -point Likert type (11 items) \\
Family postprogram fruit and vegetable consumption (post-FFB) & 11.36 & 4.65 & 412 & 33 possible fruits and vegetables \\
Household postprogram fruit and vegetable availability (post-HFA) & 9.27 & 5.24 & 414 & 27 possible fruits and vegetables \\
Youth postprogram fruit and vegetable interest (post-YFI) & 13.96 & 6.33 & 690 & 27 possible fruits and vegetables
\end{tabular}

Table 4. Youth healthy food choice self-efficacy and fruit and vegetable consumption diversity paired $t$ tests showing significant increases in both variables following Eat Your Way to Better Health program participation.

\begin{tabular}{|c|c|c|c|c|c|c|c|c|}
\hline Variable & Cases (no.) & $\begin{array}{l}\text { Pretest mean } \\
(1-4 \text { scale })\end{array}$ & SD & $\begin{array}{l}\text { Post-test mean } \\
(1-4 \text { scale })\end{array}$ & SD & Mean difference & SD & $P$ value \\
\hline $\begin{array}{l}\text { Youth healthy food choice } \\
\text { self-efficacy }\end{array}$ & 674 & 3.03 & 0.69 & 3.11 & 0.72 & 0.08 & 0.62 & 0.01 * \\
\hline $\begin{array}{l}\text { Youth fruit and vegetable } \\
\text { consumption diversity }\end{array}$ & 769 & 9.08 & 5.88 & 10.71 & 6.28 & 1.63 & 5.84 & $<0.01^{*}$ \\
\hline
\end{tabular}

${ }^{z}$ Self-efficacy mean index contained 11 items (Light, 2007); 1 = disagree a lot; 2 = disagree a little; $3=$ agree a little; $4=$ agree a lot. Higher scores were more positive in regards to self-efficacy.

${ }^{\mathrm{y}}$ Fruit and vegetable index is number of diverse fruit and vegetable items consumed per week.

${ }^{*}$ Significant at $P<0.05$. 
plays a role in youth fruit and vegetable consumption.

Another key finding was that family fruit and vegetable consumption (as reported by the parent/ guardian) was related to youth fruit and vegetable consumption upon completion of the program. This finding supports that parents/guardians can be seen as an environmental factor that plays a role in informing behaviors. In addition, this confirms the findings of previous studies (Benton, 2004; Blanchette and Brug, 2005; Boutelle et al., 2007; Bower and Sandall, 2002; Brug et al., 2008; Nanney et al., 2007; RobinsonO'Brien et al., 2009; Scaglioni et al., 2008), which found a connection between family and youth fruit and vegetable consumption.

Youth also reported a higher level of fruit and vegetable consumption diversity upon completion of the program. However, the strongest relationship with youth postprogram fruit and vegetable consumption was with youth preprogram fruit and vegetable consumption $(r=0.54)$, which suggests eating a variety of fruits and vegetables before the program was related to eating a variety of fruits and vegetables after the program (i.e., previous behavior informs current behavior). EYWTBH was a relatively brief program (8-12 weeks in length including pre- and postprogram questionnaire administration), and while other variables were also related to consumption, this result shows that food consumption behavior can be persistent, and it can be difficult to make a large difference in such a behavior over a relatively brief period of time. This finding supported previous research, which found that food consumption behaviors are very conservative (Jager, 2003; O'Donnell and Yamauchi, 2005).

One implication that emerges from this study is that food behaviors, especially youth food behaviors, are a complex, community-based, and systemic issue. The results show that there can be several variables that correlate with youth fruit and vegetable consumption. Although the EYWTBH program aimed to address multiple variables, future program offerings should include more parental/ guardian involvement in the education process wherever possible, because two variables related with youth fruit and vegetable consumption were household fruit and vegetable availability and family fruit and vegetable consumption.

One potential area for future focus could be the availability of healthy snacks in the home. This could provide an additional emphasis on the need for healthy food consumption, so that an improvement of youth fruit and vegetable consumption can more confidently represent a replacement of caloric-dense food intake instead of an addition to existing caloric intake.

This study also confirms the findings of prior research (Dirks and Orvis, 2005; Klemmer et al., 2005) regarding garden-based education as an effective pedagogical tool. The multisensory educational opportunities of EYWTBH were embedded within the curriculum to connecting youth with their food through a gardening experience. The connection between growing food and healthy food choices appears to have been made by youth. Therefore, school garden educators should continue to explore how these connections are made and developed. Although not collected in this study, future studies should collect demographic data, which can help determine program benefits for particular population segments.

Another factor to consider is that EYWTBH was an extension program implemented in a midwestern U.S. state with a Cooperative Extension Service office in every county. Therefore, the methods of this study could be transferable to other midwestern U.S. states that have a similar extension system to replicate the integration among extension, schools, and the community that was seen in EYWTBH. Finally, the results and claims were limited due to the study being a sample of convenience. Although this descriptive study provided meaningful findings, EYWTBH should be studied moving forward using quasi-experimental or experimental designs to support causal program outcome claims. Future studies should also consider using observations and interviews to help triangulate with the self-reported data.

\section{Literature cited}

Awa, N.E. and L. Van Crowder, Jr. 1978. How extension stacks up. J. Ext. 16(3).
28 Dec. 2015. <http://www.joe.org/ joe/1978march/78-2-a4.pdf>.

Bandura, A. 1986. Social foundations of thought and action: A social cognitive theory. Prentice Hall, Englewood Cliffs, NJ.

Bandura, A. 1989. Human agency in social cognitive theory. Amer. Psychol. 44:1175-1184.

Benton, D. 2004. Role of parents in the determination of the food preferences of children and the development of obesity. Intl. J. Obes. 28:858-869.

Blanchette, L. and J. Brug. 2005. Determinants of fruit and vegetable consumption among 6-12-year-old children and effective interventions to increase consumption. J. Hum. Nutr. Diet. 18:431-443.

Boutelle, K., R. Birkeland, P. Hannan, M. Story, and D. Neumark-Sztainer. 2007. Associations between maternal concern for healthful eating and maternal eating behaviors, home food availability, and adolescent eating behaviors. J. Nutr. Educ. Behav. 39:248-256.

Bower, J.A. and L. Sandall. 2002. Children as consumers-snacking behaviour in primary school children. Intl. J. Consum. Stud. 26:15-26.

Brug, J., N.I. Tak, S.J. te Velde, E. Bere, and I. de Bourdeaudhuij. 2008. Taste preferences, liking and other factors related to fruit and vegetable intakes among schoolchildren: Results from observational studies. Brit. J. Nutr. 99:S7-S14.

Cason, K.L. 1999. Children are "growing healthy" in South Carolina. J. Nutr. Educ. 31:235-236.

Centers for Disease Control and Prevention. 2013. State indicator report on fruits and vegetables, 2013. Ctr. Dis. Control Prevention, U.S. Dept. Health Human Serv., Atlanta, GA.

Dirks, A.E. and K. Orvis. 2005. An evaluation of the Junior Master Gardener program in third grade classrooms. HortTechnology 15:443-447.

Dzewaltowski, D.A., P.A. Estabrooks, and J.A. Johnston. 2002. Healthy youth places promoting nutrition and physical activity. Health Educ. Res. 17:541-551.

George, D. and P. Mallery. 2003. SPSS for Windows step by step: A simple guide and reference. 11.0 update. 4th ed. Allyn Bacon, Boston, MA.

Gist, M.E. and T.R. Mitchell. 1992. A theoretical analysis of its determinants and malleability. Acad. Mgt. Rev. 17:183-211.

Heim, S., J. Stang, and M. Ireland. 2009. A garden pilot project enhances fruit and 
vegetable consumption among children. J. Amer. Dietetic Assn. 109:1220-1226.

Hilgers, K.R., C. Haynes, and J. Olson. 2008. Assessing a garden-based curriculum for elementary youth in Iowa: Parental perceptions of change. HortTechnology 18:18-23.

Jager, W. 2003. Breaking 'bad habits': A dynamical perspective on habit formation and change, p. 149-160. In: L. Hendrickx, W. Jager, and L. Steg (eds.). Human decision making and environmental perception. Understanding and assisting human decision making in real-life settings. Univ. Groningen, Groningen, The Netherlands.

Johnson, D., L. Smith, and B. Bruemmer. 2007. Small-grants programs: Lessons from community-based approaches to changing nutrition environments. J. Amer. Dietetic Assn. 107:301-305.

Junior Master Gardener. 2014. Home. 5 Oct. 2015. <http://www.jmgkids.us>.

Klemmer, C.D., T.M. Waliczek, and J.M. Zajicek. 2005. Development of a science achievement evaluation instrument for a school garden program. HortTechnology 15:433-438.

Libman, K. 2007. Growing youth growing food: How vegetable gardening influences young people's food consciousness and eating habits. Appl. Environ. Educ. Commun. 6:87-95.

Light, H.A. 2007. Junior Master Gardener health and nutrition from the garden: An evaluation of a twelve week pilot program. MS Thesis, Purdue Univ., West Lafayette, IN.

Nanney, M., S. Johnson, M. Elliott, and D. Haire-Joshu. 2007. Frequency of eating homegrown produce is associated with higher intake among parents and their preschool-aged children in rural Missouri. J. Amer. Dietetic Assn. 107:577-584.

O’Donnell, C.R. and L. Yamauchi. 2005. Culture and context in human behavior change: Theory, research, and applications. Peter Lang, New York, NY.

Ogden, C.L., M.D. Carroll, B.K. Kit, and K.M. Flegal. 2014. Prevalence of childhood and adult obesity in the United States, 20112012. J. Amer. Medical Assn. 311:806-814.

Pant, M. 2008. Participatory training methodology and materials. 5 Oct. 2015. <http://www.unesco.org/education/ aladin/paldin/pdf/course01/unit_12. pdf $>$.

Reynolds, K.D., A.W. Hinton, R.M. Shewchuk, and C.A. Hickey. 1999. Social cognitive model of fruit and vegetable consumption in elementary school children. J. Nutr. Educ. 31:23-30.
Robinson-O'Brien, R, D. Neumark-Sztainer, P.J. Hannan, T. Burgess-Champoux, and J. Haines. 2009. Fruits and vegetables at home: Child and parent perceptions. J. Nutr. Educ. Behav. 41:360-364.

Scaglioni, S., M. Salvioni, and C. Galimberti. 2008. Influence of parental attitudes in the development of children eating behaviour. Brit. J. Nutr. 99:S22-S25.

Smith, J., L. Black, and L. Williams. 2012. Emergency exercise participation and evaluation. J. Ext. 50(3):5 Oct. 2015. <http://www.joe.org/joe/2012june/ comm2.php $>$.

Strecher, V.J., B. McEvoy DeVellis, M.H. Becker, and I.M. Rosenstock. 1986. The role of self-efficacy in achieving health behavior change. Health Educ. Behav. 13:73-92.

Taylor, J.P., S. Evans, and M. McKenna. 2005. Determinants of healthy eating in children and youth. Can. J. Public Health 96(3):S20-S26.

Vereecken, C., W. Vandamme, and L. Maes. 2005. Measuring attitudes, self-efficacy, and social and environmental influences on fruit and vegetable consumption of 11- and 12year-old children: Reliability and validity. J. Amer. Dietetic Assn. 105:257-261. 